\title{
ОБЪЕКТИВНЫЕ ПРИЗНАКИ СОСТАВОВ ПРЕСТУПЛЕНИЙ, ПРЕДУСМОТРЕННЫХ СТ. $322^{2}, 322^{3}$ УГОЛОВНОГО КОДЕКСА РФ
}

\begin{abstract}
АНнотАЦия. В статье рассматриваются объективные признаки фиктивной регистрации гражданина Российской Федерации по месту пребывания или по месту жительства в жилом помещении в Российской Федерации и фиктивной регистрации иностранного гражданина или лица без гражданства по месту жительства в жилом помещении в Российской Федерации (ст. $322^{2}$ Уголовного кодекса РФ), а также фиктивной постановки на учет иностранного гражданина или лица без гражданства по месту пребывания в жилом помещении в Российской Федерации (ст. $322^{3}$ Уголовного кодекса РФ). Делается вывод о том, что криминализация указанных составов обусловлена рядом объективных обстоятельств, среди которых можно назвать предупреждение и предотвращение более опасных преступлений. Это связано с тем, что действия, составляющие объективную сторону рассматриваемых составов, могут влиять на причины и условия совершения более тяжких преступлений, посягающих на национальную безопасность Российской Федерации.
\end{abstract}

кЛючЕВыЕ словА. Фиктивная регистрация; фиктивная постановка на учет; место жительства; место пребывания; преступление; иностранный гражданин; лицо без гражданства.

ИНФОРМАЦИЯ О СТАТЬЕ. Дата поступления 27 июня 2016 г.; дата принятия к печати 26 июля 2016 г.; дата онлайн-размещения 30 сентября 2016 г.

E. A. Laikova

East-Siberian Institute of MIA of Russia, Irkutsk, Russian Federation

\section{OBJECTIVE EVIDENCES OF COMPONENTS OF CRIME PROVIDED BY ARTICLES $322^{2}, 322^{3}$ OF RF CRIMINAL CODE}

\begin{abstract}
The article deals with objective evidences of fictitious registration of a citizen of the Russian Federation at the place of stay or a residence in premises in the Russian Federation and fictitious registration of a foreign citizen or a person without citizenship in a residence in premises in the Russian Federation (article $322^{2}$ of the Criminal Code), as well as fictitious registration of a foreign citizen or a person without citizenship in the place of stay in premises in the Russian Federation (article $322^{3}$ of the RF Criminal Code). A conclusion is made that criminalization of these components is caused by several objective factors which include caution and prevention of more dangerous crimes. This is due to the fact that the actions constituting the objective party of the considered components can affect the causes and conditions of committing more serious crimes encroaching the national security of the Russian Federation.

KEYWORDS. Fictitious registration; fictitious registration; place of residence; place of stay; crime; foreign citizen; stateless person.

ARTICLE INFO. Received June 27, 2016; accepted July 26, 2016; available online September 30, 2016.
\end{abstract}

Уголовный кодекс Российской Федерации (УК РФ) в декабре 2013 г. ${ }^{1}$ был дополнен ст. $322^{2}$ и $322^{3}$, закрепляющими ответственность за фиктивную регистрацию гражданина Российской Федерации по месту пребывания или по месту жи-

${ }^{1} \mathrm{O}$ внесении изменений в отдельные законодательные акты Российской Федерации : федер. закон РФ от 21 дек. 2013 г. № 376-ФЗ // Российская газета. 2013. 25 дек.

(C) E.A.Лайкова, 2016

\section{Baikal Research Journal}


тельства в жилом помещении в Российской Федерации и фиктивную регистрацию иностранного гражданина или лица без гражданства по месту жительства в жилом помещении в Российской Федерации, а также за фиктивную постановку на учет иностранного гражданина или лица без гражданства по месту пребывания в жилом помещении в Российской Федерации.

В юридической литературе отмечается, что криминализация деяний, связанных, в частности, с фиктивной регистрацией иностранных граждан или лиц без гражданства по месту жительства в жилом помещении в Российской Федерации, а также фиктивной постановки на учет иностранных гражданин или лиц без гражданства по месту пребывания в жилом помещении в Российской Федерации, обусловлена, в том числе, существенным ростом количества фиктивной регистрации иностранных граждан, что подрывает деятельность миграционного учета и затрудняет прогнозирование миграционной ситуации [1, с. 68].

Целью указанных дополнений уголовного закона, на наш взгляд, являлось, усиление ответственности за нарушение правил регистрационного учета граждан Российской Федерации по месту пребывания и по месту жительства и фиктивной регистрации иностранного гражданина или лица без гражданства по месту жительства в жилом помещении в Российской Федерации и фиктивной постановки на учет иностранного гражданина и лица без гражданства по месту пребывания в пределах России.

Речь идет не только об уголовной ответственности должностных лиц, осуществляющих собственно регистрационный учет граждан, но и общем субъекте преступления - физические лица, регистрирующиеся на законном основании в жилом помещении, но не имеющие намерения пребывать (проживать) в таком помещении, либо наниматели (собственники) жилых помещений, которые регистрируют на законном основании граждан Российской Федерации по месту жительства или по месту пребывания, но в то же время не имеют намерения предоставить жилое помещение для пребывания (проживания) указанных лиц.

По этой причине органы регистрационного учета не имеют возможности направлять достоверные сведения о реальном месте жительства граждан России в налоговые органы (ст. 85 Налогового кодекса РФ), военные комиссариаты (ст. 4 Федерального закона «О воинской обязанности и военной службе» от 28 марта 1998 г. № 53-Ф3), судебные органы и другие государственные органы при исполнении возложенных на них в соответствии с законодательством Российской Федерации функций. Органы миграционного учета не могут предоставлять также информацию о местонахождении иностранных граждан и лиц без гражданства, зарегистрированных в «резиновых" домах и квартирах, заинтересованным федеральным органам исполнительной власти. Это затрудняет прогнозирование миграционной ситуации и нивелирует саму идею миграционного учета. Эффективность изложенных позиций, тем не менее, обуславливается не количеством уголовно-правовых запретов, а качеством: логичностью и ясностью используемой терминологии, отсутствием внутренних противоречий, избыточности, системностью норм [2, с. 19].

П. Филиппов отмечает, что можно было бы согласиться с введением уголовной ответственности за фиктивную регистрацию, если бы обязательным признаком данных составов была, например, системность действий или иные признаки, указывающие на то, что лицо занимается такой регистрацией на постоянной основе и извлекает из этого прибыль или доход в крупном размере [3, с. 84].

Учитывая общественную опасность указанных составов преступлений, считаем, что введение уголовной ответственности за фиктивную регистрацию гражданина Российской Федерации по месту пребывания или по месту жительства в жилом помещении в Российской Федерации и фиктивную регистрацию иностранного

\section{Baikal Research Journal}

электронный научный журнал Байкальского государственного университета 
гражданина или лица без гражданства по месту жительства в жилом помещении в Российской Федерации (ст. $322^{2}$ УК РФ), а также фиктивную постановку на учет иностранного гражданина или лица без гражданства по месту пребывания в жилом помещении в Российской Федерации (ст. $322^{3}$ УК РФ) было целесообразным и своевременным.

Это объясняется рядом обстоятельств, среди которых можно выделить направленные на предупреждение и предотвращение других, более опасных преступлений и влияющие на причины и условия, способствующие совершению тяжких преступлений (например, подделка документов, приобретение оружия для совершения убийства, хищение человека для трансплантации органов и тканей на «черном рынке», незаконный оборот наркотиков).

Кроме того, указанные деяния являются одним из последствий незаконной миграции, которая влияет на национальную безопасность России [4, с. 40]. На заседании Совета Безопасности РФ 30 марта 2016 г. Президент РФ отметил, что эффективный контроль за массовыми миграционными потоками является вопросом безопасности всей страны [5]. Массовые миграционные потоки иностранных граждан и лиц без гражданства приводят к стихийному росту населения, а также к ухудшению криминогенной обстановки как на региональном уровне, так и на общероссийском. Неконтролируемые потоки беженцев порождают конфликты, возникающие на национальной и религиозной почве, вызывают социальное напряжение в обществе.

Таким образом, нелегальная миграция затрагивает большинство сфер жизнедеятельности общества. Если говорить о политической сфере, то в ней незаконная миграция выступает непосредственной угрозой геополитическим интересам государства. В экономической сфере она способствует увеличению масштабов теневой экономики вне налогового пространства, обострению ситуации на рынке занятости населения. В социальной сфере, как уже отмечалось, незаконная миграция приводит к социальному напряжению, осложнению криминальной обстановки. Отсюда следует, что миграционные процессы в Российской Федерации показывают, что проблемы с незаконной миграцией продолжают оставаться достаточно острыми [6, с. 38]. Ежегодно в России выявляются сотни так называемых «резиновых» квартир, в которых регистрируются сотни мигрантов без намерения в них вселяться и проживать, а реальное их место жительства остается неизвестным.

Об общественной опасности рассматриваемых противоправных деяний свидетельствует уже появившаяся на данный момент судебно-следственная практика, отраженная в статистических данных Судебного департамента при Верховном Суде Российской Федерации (табл.).

Число лиц, осужденных за совершение преступлений в 2014-2015 г2., предусмотренных $\mathrm{cm} .322^{2}$ и $322^{3}$ Уголовного кодекса РФ

\begin{tabular}{|l|r|r|}
\hline \multicolumn{1}{|c|}{ Нормативная статья } & 2014 & \multicolumn{1}{|c|}{2015} \\
\hline $322^{2}$ & 223 & 486 \\
\hline $322^{3}$ & 3344 & 5543 \\
\hline
\end{tabular}

Составлено по: Данные статистики судебного департамента при Верховном суде Российской Федерации за 2014-2015 гг. [Электронный ресурс]. URL : wwwcdep.ru.

Одним из примеров может служить приговор мирового судьи участка № 24 Ленинского районного суда г. Иркутска, которым гр. С. был признан виновным в совершении фиктивной постановки на учет иностранных граждан по месту пребывания в жилом помещении в Российской Федерации.

С., являясь гражданином Российской Федерации, обладая информацией о необходимости с целью соблюдения установленного порядка регистрации, передви-

\section{Baikal Research Journal}

электронный научный журнал Байкальского государственного университета 
жения и выбора места жительства иностранным гражданам или лицам без гражданства уведомлять органы миграционного контроля об их месте пребывания и понимая, что без данного уведомления их пребывание на территории Российской Федерации незаконно, а также не имея намерения предоставить место пребывания иностранным гражданам или лицам без гражданства, действуя во исполнение своего преступного умысла, поставил на миграционный учет по месту пребывания в принадлежащей ему квартире через отдел ГАУ «МФЦ ИО» двух иностранных граждан на период с 1 июня 2015 г. по 15 сентября 2015 г. Он заполнил уведомления, которые заверил своей подписью, указав факт их временного пребывания на территории Российской Федерации по адресу своей регистрации, заведомо зная, что иностранные граждане проживать в принадлежащей ему квартире по определенному адресу не будут, чем самым совершил фиктивную постановку на учет иностранных граждан по месту пребывания в жилом помещении в Российской Федерации, фактически не являясь принимающей стороной и не предоставляя места пребывания иностранным гражданам, действуя во исполнение своего преступного умысла, направленного на извлечение прибыли с иностранных граждан. $К$ нему была применена мера наказания в виде штрафа ${ }^{2}$.

Примером преступления, предусмотренного ст. $322^{2}$ УК РФ, может служить следующие противоправное деяние. Приговором мирового судьи судебного участка № 1 Матвеево-Курганского района Ростовской области, гр.М. была признана виновной в совершении фиктивной регистрации гражданина Российской Федерации по месту жительства в жилом помещении в Российской Федерации.

Имея преступный умысел, направленный на фиктивную регистрацию гражданина Российской Федерации по месту жительства в жилом помещении в Российской Федерации, осознавая, что она как принимающая сторона не имеет намерения предоставить гр. Л. жилое помещение, принадлежащее гр. М. на праве собственности, расположенного по определенному адресу, гр. М. обратилась в Межрайонное отделение УФМС России по Ростовской области с целью фиктивной регистрации гражданина Российской Федерации. Продолжая свой преступный умысел, гр. М. в нарушение Постановления Правительства РФ «Об утверждении правил регистрации и снятия граждан Российской Федерации с регистрационного учета по месту пребывания и по месту жительства в пределах Российской Федерации и перечня должностных лиц, ответственных за регистрацию» от 17 июля 1995 г. № 713, «предоставила начальнику Межрайонного отделения УФМС России по Ростовской области в поселке Матвеев-Курган заявление гражданина Российской Федерации о регистрации по месту пребывания № 32 , заявление о регистрации гражданина Российской Федерации по месту жительства, свидетельство о государственной регистрации права, согласно которому она является собственником домовладения.

Начальник Межрайонного отделения Управления Федеральной Миграционной службы по Ростовской области в пос. Матвеев-Курган на основании предоставленных гр. М. заведомо недостоверных сведений о месте регистрации гражданки Российской Федерации, зарегистрировала гр. Л. по месту жительства в жилом помещении без намерения последней проживать по месту регистрации ${ }^{3}$.

В представленных уголовных делах о преступлениях, предусмотренных ст. $322^{2}$, $322^{3}$ УК РФ, к уголовной ответственности за регистрацию гражданина Российской Федерации по месту пребывания или по месту жительства в жилом помещении в Российской Федерации и фиктивную регистрацию иностранного гражданина или

${ }^{2}$ Приговор мирового судьи участка № 24 Ленинского района г. Иркутска от 20 августа 2014 года № 1-53/2014.

${ }^{3}$ Приговор мирового судьи участка № 1 Матвеево-Курганского района, Ростовской области от 1 октября 2015 г. № 1-29/2015.

\section{Baikal Research Journal}

электронный научный журнал Байкальского государственного университета 
лица без гражданства по месту жительства в жилом помещении в Российской Федерации, а также за фиктивную постановку на учет иностранного гражданина или лица без гражданства по месту пребывания в жилом помещении в Российской Федерации, были привлечены собственники жилых помещений.

Совершенные ими преступления характеризуются деянием в форме активного поведения, выражающегося фиктивной регистрацией гражданина Российской Федерации по месту пребывания или по месту жительства в жилом помещении в Российской Федерации и фиктивной регистрацией иностранного гражданина или лица без гражданства по месту жительства в жилом помещении в Российской Федерации, а также фиктивной постановкой на учет иностранного гражданина или лица без гражданства по месту пребывания в жилом помещении в Российской Федерации, без намерения предоставить им это помещение для пребывания (проживания) путем представления в орган миграционного учета заведомо недостоверных (ложных) сведений или документов, уведомлений, содержащих заведомо недостоверные (ложные) сведения о перечисленных фактах. Отсюда следует, что основную угрозу в крупных городах и мегаполисах создают именно иногородние граждане и лица без гражданства, ими совершается практически половина всех преступлений из числа раскрытых [7, с. 59].

В связи с тем, что рассматриваемые составы преступлений появились в УК РФ сравнительно недавно, требуется провести уголовно-правовой анализ их объективных признаков. Рассмотрим объект и объективную сторону преступлений, предусмотренных ст. $322^{2}, 322^{3}$ УК РФ. В соответствии с ч. 2 ст. 15 УК РФ составы преступлений, предусмотренные ст. $322^{2}$ и $322^{3}$ УК РФ, относятся к категории преступлений небольшой тяжести.

По мнению Е. В. Роговой, преступления небольшой тяжести за последние несколько лет стабильно доминируют, это связано, в том числе, и с изменениями, внесенными в уголовный закон в декабре 2011 г. в отношении преступлений небольшой тяжести, к которым стали относится умышленные и неосторожные деяния, за совершение которых максимальное наказание, предусмотренное УК РФ, не превышает трех лет лишения свободы [8, с. 40].

Объект преступления - это охраняемое уголовным правом общественное отношение, против которого прямо и непосредственно направлено одно или несколько преступлений. Объективная сторона состава преступления - это внешний аспект преступного проявления, выраженный общественно опасным деянием в форме действия или без действия, общественно опасным последствием и наличии прямой причинно-следственной связи между совершенным деянием и наступившим последствием, а также отраженный во времени, в обстановке, месте, способе, орудии, средстве совершения преступления.

К обязательным признакам объективной стороны относятся уголовно-противоправное (общественно опасное) деяние (действие или бездействие), общественно опасное последствие, возникшее в результате совершения противоправного деяния $[9$, c. 12].

Б. С. Никифоров писал, что «объект преступления - это тот общественный интерес, против которого направляется преступление, которое берет под свою защиту уголовное право» $[10$, с. 4$]$.

Анализ составов преступлений, предусмотренных ст. $322^{2}, 322^{3}$ УК РФ - это и есть те объективные признаки, которые заявлены в названии. В. Н. Кудрявцев, обращая внимание на взаимосвязь объекта и объективной стороны, отмечал, что объективная сторона характеризует «главным образом внешние формы процесса посягательства на охраняемый законом объект» $[11$, с. 8] и определяется через содержание общественных отношений, поставленных под охрану.

\section{Baikal Research Journal}


Сущность объекта фиктивной регистрации гражданина Российской Федерации по месту пребывания или месту жительства в жилом помещении в Российской Федерации и фиктивной регистрации иностранного гражданина или лица без гражданства по месту жительства в жилом помещении в Российской Федерации и фиктивной постановки на учет иностранного гражданина и лица без гражданства по месту пребывания в жилом помещении в Российской Федерации основано на определении содержания общего объекта преступления, под которым понимаются «те общественные отношения, на которые посягает преступление, т. е. на что оно направлено, что нарушает и чему причиняет или может причинить вред» [12, с. 62].

Выявление сущности объекта фиктивной регистрации гражданина Российской Федерации по месту пребывания или по месту жительства в жилом помещении в Российской Федерации и фиктивной регистрации иностранного гражданина или лица без гражданства по месту жительства в жилом помещении в Российской Федерации, а также фиктивной постановки на учет иностранного гражданина и лица без гражданства по месту пребывания в жилом помещении в Российской Федерации следует начинать с определения его места в системе общественных отношений, охраняемых гл. 32 УК РФ, которые возникают, развиваются и прекращаются в сфере реализации государственной власти, интересов порядка управления.

Объектом преступлений против порядка управления являются определенные функции органов государственной власти и регионального самоуправления, нормальное осуществление которых есть необходимое условие охраны общественного порядка и обеспечения общественной безопасности, правильного ведения служебной документации и др. Если преступление против порядка управления сопряжено с посягательством на личность сотрудников государственного аппарата или аппарата органов местного самоуправления либо их близких, непосредственным объектом преступления признаются также соответствующие законные интересы (блага) личности (жизнь и здоровье человека, его честь и достоинство) [13, с. 463$]$.

Непосредственным объектом преступлений, предусмотренных ст. $322^{2}$ и $322^{3}$ УК РФ, являются общественные отношения и установленный порядок регистрации граждан по месту пребывания или месту жительства и постановки на учет иностранных граждан и лиц без гражданства в жилых помещениях Российской Федерации, так как регистрационный учет установлен в целях обеспечения необходимых условий для реализации гражданами своих прав и свобод, а также исполнения ими обязанностей перед другими гражданами, государством и обществом.

Объективная сторона преступления, предусмотренного ст. $322^{2}$ и $322^{3}$ УК РФ, выражается в действии и заключается в осуществлении вымышленной регистрации по месту пребывания или по месту жительства. Фиктивность регистрации выражается в том, что она осуществляется, соответственно, выдается свидетельство о регистрации или делается отметка о регистрации в паспорте при недостаточности или полном отсутствии оснований для совершения таких действий.

Регистрация иностранцев, въезжающих в то или иное государство - это обычная процедура для всех стран мира. Конечно, тонкости данного процесса в каждой стране свои, но суть регистрации иностранцев едина - это государственный контроль за перемещением граждан.

Миграционная политика нашего государства такова, что помимо обязательной регистрации граждан РФ (по месту жительства или по месту пребывания) встать на регистрационный учет обязаны и все иностранные лица, въезжающие на территорию России. В связи с возросшей в последние годы активностью населения и частыми поездками людей в другие страны необходимо определить понятия, что является «местом пребывания» и «местом жительства», с разъяснением вопроса о том, в каком режиме могут въехать на территорию страны иностранные граждане. Въезд

\section{Baikal Research Journal}

электронный научный журнал Байкальского государственного университета 
на территорию Российской Федерации может осуществляться иностранными гражданами как по визам, так и в безвизовом режиме.

В безвизовом режиме (без получения визы) на территорию России могут въехать:

- иностранные граждане ближнего зарубежья (граждане стран СНГ);

- иностранные граждане дальнего зарубежья, со страной гражданства которых у России имеется соглашение о безвизовом посещении иностранцами России на срок до 1 месяца;

- иностранные граждане, имеющие разрешение на временное проживание в Российской Федерации;

- иностранные граждане, имеющие вид на жительство в Российской Федерации.

Итак, после того, как иностранный гражданин въехал на территорию России, он должен зарегистрироваться - это может быть регистрация либо по месту пребывания, либо по месту жительства.

Место пребывания - гостиница, дом отдыха, пансионат, санаторий, кемпинг, туристская база, медицинская организация или другое подобное учреждение, учреждение уголовно-исполнительной системы, исполняющее наказания в виде лишения свободы или принудительных работ, либо не являющееся местом жительства гражданина Российской Федерации жилое помещение, в котором он проживает временно. Регистрация гражданина по месту пребывания производится в срок, не превышающий 90 дней со дня прибытия гражданина в жилое помещение. Регистрация по месту пребывания производится без снятия гражданина с регистрационного учета по месту жительства (исключение - если человек находится в местах лишения свободы, тогда снимается с учета).

Место жительства - жилой дом, квартира, комната, жилое помещение специализированного жилищного фонда (служебное жилое помещение, жилое помещение в общежитии, жилое помещение маневренного фонда, жилое помещение в доме системы социального обслуживания населения и др.) либо иное жилое помещение, в которых гражданин постоянно или преимущественно проживает в качестве собственника, по договору найма (поднайма), договору найма специализированного жилого помещения либо на иных основаниях, предусмотренных законодательством Российской Федерации, и в которых он зарегистрирован по месту жительства ${ }^{4}$.

Ст. $322^{2}$ УК РФ включает в себя два состава преступления, которыми может быть совершенно данное преступление:

- фиктивная регистрация гражданина Российской Федерации по месту пребывания или по месту жительства в жилом помещении в Российской Федерации;

- фиктивная регистрация иностранного гражданина или лица без гражданства по месту жительства в жилом помещении в Российской Федерации.

Под фиктивной (вымышленной) регистрацией понимается представление заведомо недостоверных сведений или документов для такой регистрации, либо его регистрация в жилом помещении без намерения пребывать (проживать) в этом помещении, либо регистрация гражданина России по месту пребывания или по месту жительства без намерения нанимателя (собственника) жилого помещения предоставить это жилое помещение для пребывания (проживания) указанного лица 5 .

В ст. $322^{3}$ УК РФ объективная сторона характеризуется деянием в форме активного поведения-действия, выражающегося в фиктивной постановке на учет ино-

${ }^{4}$ Правила регистрации и снятия граждан РФ с регистрационного учета по месту пребывания и по месту жительства в пределах Российской Федерации, утв. постановлением Правительства РФ от 17 июля 1995 г. № 713 // Российская газета. 1995. 27 июля.

${ }^{5}$ О праве граждан Российской Федерации на свободу передвижения, выбор места пребывания и жительства в пределах Российской Федерации [Электронный ресурс] : закон РФ от 25 июня 1993 г. № 5242-1 (ред. от 28 нояб.2015 г.) // СПС «КонсультантПлюс».

\section{Baikal Research Journal}

электронный научный журнал Байкальского государственного университета 
странных граждан и лиц без гражданства по месту пребывания в жилом помещении в Российской Федерации. Фиктивной считается постановка на учет иностранных граждан и лиц без гражданства по месту пребываниив жилых помещениях на основании представления заведомо недостоверных (ложных) сведений либо документов и постановки их на учет по месту пребывания в жилых помещениях без намерения пребывать (проживать) в этих помещениях или без намерения принимающей стороны предоставить им эти помещения для пребывания (проживания).

Согласно п. 1 и 6 ст. 2 Федерального закона «О миграционном учете иностранных граждан и лиц без гражданства в РФ» от 18 июля 2006 г. № 109-ФЗ учет иностранного гражданина и лица без гражданства по месту пребывания - это фиксация в установленном порядке уполномоченными органами сведений о нахождении иностранного гражданина либо лица без гражданства в месте пребывания. В соответствии с п. 1 и 7 ст. 2 этого же закона под «принимающей стороной» понимается, в том числе, гражданин РФ, постоянно проживающий в РФ иностранный гражданин или лицо без гражданства, у которых иностранный гражданин либо лицо без гражданства фактически проживает либо осуществляет трудовую деятельность (находится). Обязательными действиями принимающей стороны, выполняемыми ею в процессе осуществления постановки иностранных граждан на учет по месту пребывания, определены п. 2 подп. 2 ст. 22 Федерального закона «О миграционном учете иностранных граждан и лиц без гражданства в РФ» от 18 июля 2006 г. № 109-ФЗ и включают в себя:

- предоставление в орган миграционного учета уведомления о прибытии иностранного гражданина в место пребывания;

- передачу иностранному гражданину отрывной части бланка уведомления ${ }^{6}$.

Отсюда следует, что объективной стороной состава преступления, предусмотренного ст. $322^{3}$ УК РФ, в случае совершения его гражданином, фиктивно принимающем участие в постановке на учет иностранного гражданина как «принимающая сторона», является предоставление таким гражданином в орган миграционного учета сведений о пребывании в его жилом помещении иностранного гражданина путем подачи подписанного им бланка уведомления, содержащего соответствующие сведения.

Главным признаком объективной стороны преступления является отсутствие у гражданина в момент совершения описанных действий намерения фактически предоставить жилое помещение иностранному гражданину для пребывания. Рассматриваемые нами преступления по конструкции имеют формальный состав, т. е. для признания их оконченными достаточно установить осуществление фиктивной регистрации (постановки на учет) и фиктивной постановки на учет иностранных граждан и лиц без гражданства по месту пребывания в жилом помещении в Российской Федерации. Следовательно, окончательным временем совершения преступления является время подачи им в орган миграционного учета уведомления о прибытиии иностранного гражданина или лица без гражданства.

Изложенные факты позволяют сделать следующие выводы, что фиктивная регистрация гражданина Российской Федерации по месту пребывания или по месту жительства в жилом помещении в Российской Федерации и фиктивная регистрация иностранного гражданина или лица без гражданства по месту жительства в жилом помещении в Российской Федерации, фиктивная постановка на учет иностранного гражданина или лица без гражданства по месту пребывания в жилом помещении в Российской Федерации могут быть осуществлены только путем действий, кото-

${ }^{6} \mathrm{O}$ миграционном учете иностранных граждан и лиц без гражданства в Российской Федерации : федер. закон РФ от 18 июля 2006 г. № 109-ФЗ // Собрание законодательства РФ. 2006. № 30. Ст. 3285.

\section{Baikal Research Journal}

электронный научный журнал Байкальского государственного университета 
рые могут заключаться в разработке способов фиктивной регистрации и фиктивной постановки на миграционный учет в жилом помещении в Российской Федерации, поиске лиц, желающих фиктивно зарегистрироваться или встать на миграционный учет, обеспечении их соответствующими документами, установлении незаконных контактов с лицами, осуществляющими государственную услугу по регистрационному учету граждан Российской Федерации, по месту пребывания и по месту жительства в пределах России. Деяние будет являться оконченным с момента совершения любого из перечисленных действий.

\section{Список использованной литературы}

1. Ахмедов М. Н. Некоторые вопросы уголовно-правового противодействия незаконному пребыванию на территории Российской Федерации / М. Н. Ахмедов // Вестник Владимирского юридического института. - 2015. - № 4 (37). - С. 67-71.

2. Дядюн К. В. Проблемы регламентации уголовно-правовой ответственности за незаконную миграцию / К. В. Дядюн // Академический юридический журнал. - 2013. № 1 (51). - C. 19-27.

3. Филиппов П. Организация незаконной миграции практика применения ст. 322.1 УК РФ и новеллы законодательства / П. Филиппов // Уголовное право. - 2014. - № 3. - С. 83-92.

4. Ишигеев В. С. Миграция и национальная безопасность России / В. С. Ишигеев, М. Е. Авдеев // Вестник Восточно-Сибирского института МВД России. — 2015. - № 4 (75). C. $40-42$.

5. Путин В. В. Выступление Президента Российской Федерации В. В. Путина на заседании Совета безопасности от 31 марта 2016 г. [Электронный ресурс] / В. В. Путин. - Режим доступа : http://www.kremlin.ru/events/president/news/51618.

6. Волокитина М. В. Незаконная миграция в России: причины и сущность явления / М. В. Волокитина // Мониторинг правоприменения. - 2013. - № 1. - С. 35-38.

7. Коваленко В. И. Этническая преступность и незаконная миграция: криминологическая оценка состояния и тенденций / В. И. Коваленко, Ф. Г. Серый // Вестник Волгоградской академии МВД России. - 2014. - № 4 (312). - С. 57-63.

8. Рогова Е. В. Криминологическая характеристика лиц, виновных в совершении преступлений небольшой тяжести / Е. В. Рогова // Вестник Казанского юридического института МВД России. - 2015. - № 2 (20). - С. 40-45.

9. Сверчков В. В. Базовый курс Уголовного права. Общая и Особенные части : учеб.для бакалавров / В. В. Сверчков. - 3-е изд., перераб. и доп. - М. : Юрайт, 2013. - 588 с.

10. Никифоров Б. С. Объект по советскому уголовному праву / Б. С. Никифоров. - М. : Госюриздат, 1960. - $232 \mathrm{c.}$

11. Кудрявцев В. Н. Объективная сторона преступлений / В. Н. Кудрявцев. - М. : Госюриздат, 1960. - $244 \mathrm{c}$.

12. Гаухман Л. Д. Квалификация преступлений: закон, теория, практика / Л. Д. Гаухман. - М. : Центр ЮрИнфоР, 2001.-316 с.

13. Уголовное право России. Особенная часть : учебник / под ред. В. Н. Кудрявцева, В. В. Лунева, А. В. Наумова. - 4-е изд., перераб. и доп. - М. : Юристъ, 2006. - 540 с.

\section{References}

1. Akhmedov M. N. Some Issues of Criminal Law Countering the Illegal Staying on the Territory of the Russian Federation. Vestnik Vladimirskogo yuridicheskogo instituta $=$ Bulletin of Vladimir Law Institute, 2015, no. 4 (37), pp. 67-71. (In Russian).

2. Dyadun K. V. Problems of regulation of criminal liability for illegal migration. Akademicheskii yuridicheskii zhurnal = Academic Juridical Journal, 2013, no. 1(51), pp. 19-27. (In Russian).

3. Filippov P. Organization of illegal migration: practice of application of article $322^{1}$ of the Criminal Code of the Russian Federation and novelties of legislation. Ugolovnoe pravo = Criminal Law, 2014, no. 3, pp. 83-92.(In Russian).

4. Ishigeev V. S., Avdeev M. E. Migration and national security of Russia. Vestnik Vostochno-Sibirskogo instituta MVD Rossii = Bulletin of East-Siberian Institute of MIA of Russia, 2015, no. 4 (75), pp. 40-42.(In Russian).

\section{Baikal Research Journal}


5. Putin V. V. Vystuplenie Prezidenta Rossiiskoi Federatsii V. V. Putina na zasedanii Soveta bezopasnosti ot 31 marta 2016 g. [Address of President of the Russian Federation V. V. Putin at the Session of the Security Counsel of March 11, 2016]. Available at: http://www.kremlin.ru/ events/president/news/51618. (In Russian).

6. Volokitina M. V. Illegal migration in Russia: the reasons and essence of the phenomenon. Monitoring pravoprimeneniya = Monitoring of Law Enforcement, 2013, no. 1, pp. 35-38. (In Russian).

7. Kovalenko V. I. Ethnic criminality and illegal migration: criminological assessment of states and trends. Vestnik Volgogradskoi akademii MVD Rossii = Bulletin of Volgograd Academy of Internal Affairs Ministry of Russia, 2014, no. 4 (312), pp. 57-63. (In Russian).

8. Rogova E. V. Criminological characteristic of persons guilty of committing crimes of minor gravity. Vestnik Kazanskogo yuridicheskogo instituta MVD Rossii= Bulletin of Kazan Juridical Institute of MIA of Russia, 2015, no. 2 (20), pp. 40-45. (In Russian).

9. Sverchkov V. V. Bazovyi kurs Ugolovnogo prava. Obshchayai Osobennye chasti [Basic Course of Criminal Law. General and Specific Parts]. $3^{\text {rd }}$ ed. Moscow, Yurait Publ., 2013. 588 p.

10. Nikiforov B. S. Ob" ekt po sovetskomu ugolovnomu pravu [The object according to Soviet Criminal Law]. Moscow, Gosyurizdat Publ., 1960. 232 p.

11. Kudryavtsev V. N. Ob"ektivnaya storona prestuplenii [Objective side of crimes]. Moscow, Gosyurizdat Publ., 1960. 244 p.

12. Gaukhman L. D. Kvalifikatsiya prestuplenii: zakon, teoriya, praktika [Qualification of crimes: law, theory, practice]. Moscow, Center YurInfoR Publ., 2001. 316 p.

13. Kudryavtsev V. N., Lunev V. V., Naumov A. V. (eds). Ugolovnoe pravo Rossii. Osobennaya chast' [Criminal Law of Russia. Specific Part.] $3^{\text {th }}$ ed.Moscow, Yurist" Publ., 2006. 540 p.

\section{Информация об авторе}

Лайкова Елена Александровна - адъюнкт, Восточно-Сибирский институт МВД России, 664074, г. Иркутск, ул. Лермонтова, 110, e-mail: elena-lajkova@yandex.ru.

\section{Author}

Elena A. Laikova - Junior Scientific Assistant, East-Siberian Institute of MIA of Russia, 110 Lermontov St., 664074, Irkutsk, Russian Federation; e-mail: elena-lajkova@yandex.ru.

\section{Библиографическое описание статьи}

Лайкова Е. А. Объективные признаки составов преступлений, предусмотренных ст. $322^{2}$, $322^{3}$ Уголовного кодекса РФ / Е. А. Лайкова // Baikal Research Journal. — 2016. - T. 7, № 5. — DOI : 10.17150/2411-6262.2016.7(5).20.

\section{Reference to article}

Laikova E. A. Objective evidences of components of crime provided by Articles $322^{2}, 322^{3}$ of RF Criminal Code. Baikal Research Journal, 2016, vol. 7, no. 5. DOI : 10.17150/24116262.2016.7(5).20. (In Russian).

\section{Baikal Research Journal}

